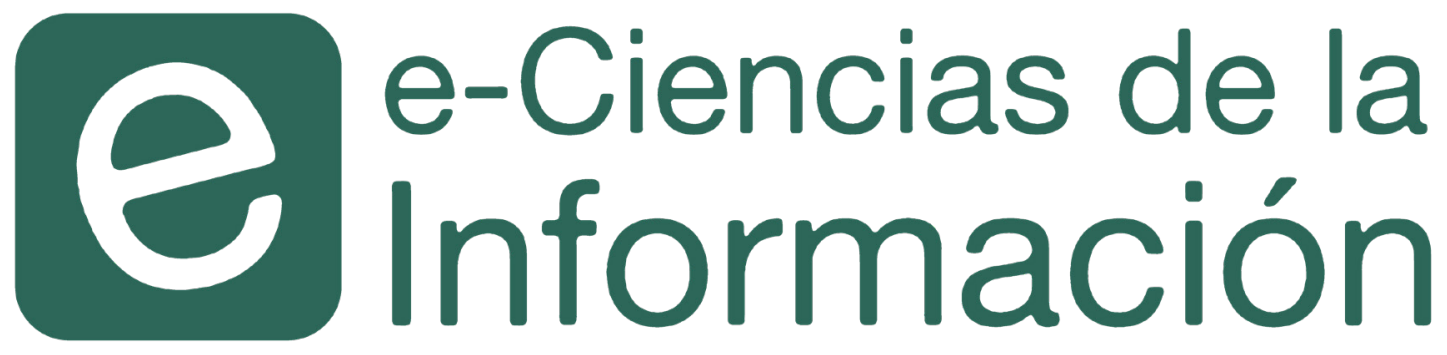

\title{
Bibliotecas digitais e virtuais à luz da literatura brasileira: da construção ao acesso
}

\section{Jorge Santa Anna Célia da Consolação Dias}

\section{Recibido: 03/05/2019 | Corregido: 23/08/2019 | Aceptado: 25/09/2019} DOI: $10.15517 /$ eci.v10i1.39882

e-Ciencias de la Información, volumen 10, número 1, Ene- Jun 2020

ISSN: 1649-4142

\section{다(1)\$()}

\section{¿Cómo citar este artículo?}

Santa Anna, J. y da Consolação Dias, C. (2020). Bibliotecas digitais e virtuais à luz da literatura brasileira: da construção ao acesso. e-Ciencias de la Información, 10(1). DOI: 10.15517/eci.v10i1.39882 


\title{
Bibliotecas digitais e virtuais à luz da literatura brasileira: da construção ao
}

\section{acesso}

\author{
Bibliotecas digitales y virtuales a la luz de la literatura \\ brasileña: de la construcción al acceso
}

\author{
Digital and virtual libraries in the light of brazilian liter- \\ ature: from construction to access \\ Jorge Santa Anna (D) ${ }^{1}$ \\ Célia da Consolação Dias (D) ${ }^{2}$
}

\section{RESUMO}

Os reflexos das tecnologias da informação e comunicação nas bibliotecas é tema recorrente na literatura da área de Biblioteconomia e Ciência da Informação. Este artigo constitui uma revisão de literatura sobre o tema "Bibliotecas Digitais" e "Bibliotecas Virtuais", haja vista verificar os principais assuntos discorridos na literatura, por conseguinte, apresentar aspectos quantitativos que caracterizam a produção científica sobre o tema. A pesquisa é descritiva, qualiquantitativa e foram selecionados artigos da Base de Dados de Periódicos em Ciência da Informação, SciELO e Portal de Periódicos CAPES, publicados em português, de 2010 a 2014, mediante a técnica de coleta do tipo levantamento e análise de conteúdo. Os procedimentos realizados no estudo permitiram a identificação de 21 artigos que contemplam diferentes assuntos relacionados ao tema: estruturação das bibliotecas, produtos e serviços oferecidos, educação e formação, e acesso e usabilidade da biblioteca. Os dados quantitativos analisados demonstraram haver preferência pelo termo "Bibliotecas Digitais" ao termo "Bibliotecas Virtuais", com predominância dos assuntos "estruturação de bibliotecas"e"acesso e usabilidade". Os trabalhos foram publicados de forma equilibrada, ao longo dos anos, predomínio da autoria coletiva, e houve distribuição uniforme entre boa parte dos periódicos brasileiros da Ciência da Informação/Biblioteconomia. Como principal limitação, destaca-se o uso de artigos em português, o que instiga a realização de estudos futuros em artigos publicados em inglês e espanhol, e delimitando o tempo para anos mais recentes.

Palavras-chave: Tecnologias da Informação e comunicação; Bibliotecas Digitais; Bibliotecas Virtuais; Estruturação de Bibliotecas Digitais; Acesso à informação; Usabilidade.

\section{RESUMEN}

Los reflejos de las tecnologías de la información y la comunicación en las bibliotecas son un tema recurrente en la literatura de bibliotecas y ciencias de la información. Este artículo es una revisión de la literatura sobre el tema "Bibliotecas digitales" y "Bibliotecas virtuales",

1 Universidade Federal de Minas Gerais (UFMG), BRASIL. janna@ufmg.br ORCID: http://orcid.org/00000002-0709-3639

2 Universidade Federal de Minas Gerais (UFMG), BRASIL. celiadias@eci.ufmg.br ORCID: http://orcid. org/0000-0003-0891-6454 
con el fin de verificar los principales temas discutidos en la literatura, por lo tanto, presenta aspectos cuantitativos que caracterizan la producción científica sobre el tema. La investigación es descriptiva, cualitativa y cuantitativa, y los artículos de la Base de datos periódica de ciencias de la información, SciELO y Portal Capes, publicados en portugués, de 2010 a 2014, se seleccionaron utilizando la técnica de recopilación de encuestas y el análisis de contenido. Los procedimientos realizados en el estudio permitieron la identificación de 21 artículos que cubren diferentes temas relacionados con el tema: estructuración de la biblioteca, productos y servicios ofrecidos, educación y capacitación, y acceso a la biblioteca y usabilidad. Los datos cuantitativos analizados mostraron una preferencia por el término "Bibliotecas digitales" sobre el término "Bibliotecas virtuales", con predominio de los temas "estructuración de bibliotecas" y "acceso y usabilidad". Las obras se publicaron de manera equilibrada, a lo largo de los años, predominando la autoría colectiva, y hubo una distribución uniforme entre la mayoría de las revistas brasileñas de Ciencias de la Información / Bibliotecología. La principal limitación es el uso de artículos en portugués, lo que impulsa futuros estudios en artículos publicados en inglés y español, limitando el tiempo a años más recientes.

Palabras-clave: Tecnologías de la información y la comunicación; Bibliotecas digitales; Bibliotecas virtuales; Estructuración de bibliotecas digitales; Acceso a la información; Usabilidad.

\section{ABSTRACT}

The reflexes of information and communication technologies in libraries is a recurring theme in the library and information science literature. This article is a literature review on the topic "Digital Libraries" and "Virtual Libraries", in order to verify the main subjects discussed in the literature, therefore, presenting quantitative aspects that characterize the scientific production on the subject. The research is descriptive, qualitative and quantitative, and articles from the Information Science Periodical Database, SciELO and Portal Capes, published in Portuguese, from 2010 to 2014, were selected using the survey collection technique and content analysis. The procedures performed in the study allowed the identification of 21 articles that cover different subjects related to the theme: library structuring, products and services offered, education and training, and library access and usability. The quantitative data analyzed showed a preference for the term "Digital Libraries" over the term "Virtual Libraries", with predominance of the subjects "library structuring" and "access and usability". The works were published in a balanced way, over the years, predominance of collective authorship, and there was a uniform distribution among most Brazilian journals of Information Science / Library Science. The main limitation is the use of articles in Portuguese, which prompts future studies in articles published in English and Spanish, limiting the time to more recent years.

Keywords: Information and Communication Technologies; Digital libraries; Virtual libraries; Structuring of digital libraries; Access to information; Usability. 


\section{INTRODUÇÃO}

Os reflexos provocados pelas tecnologias digitais e o uso intensificado do ambiente web têm promovido uma mudança substancial na sociedade como um todo, englobando usuários e instituições, nos mais diferenciados segmentos sociais. No âmbito informacional, profissionais e unidades inserem-se em um ciclo de transformação, haja vista atender as necessidades e tendências que se apresentam, a cada momento, por parte dos utilizadores dos produtos e serviços de informação.

Diante desse cenário, bibliotecas e bibliotecários se colocam em uma situação de adequação, visto que a permanência dessa instituição e desse profissional está ligada à capacidade de acompanhar as novidades, atendendo e satisfazendo as necessidades do público-alvo. Essa é uma característica da globalização direcionada a todas as áreas de conhecimento e profissões, sobretudo em virtude da instabilidade promovida pela competitividade do mercado.

Logo, adequar-se não é uma exigência restrita apenas a bibliotecas e bibliotecários, mas configura-se como um paradigma social que permeia todas as instâncias e contextos da sociedade. Ser competitivo e conseguir sobreviver em um mundo comandado pelas tecnologias digitais vai muito além da adequação. Requer, também, a capacidade em oferecer algo que promova um diferencial, um engajamento nos consumidores e/ou utilizadores de produtos e serviços, especialmente os de informação.

Como nos ensina Castells (2005), vivemos um processo multidimensional, que está associado à emergência de um novo paradigma tecnológico, cujas pessoas precisam ser capazes de aceitar essas tecnologias, sem necessariamente submerter-se a elas, visto que precisam utilizá-las de acordo com suas necessidades, valores e interesses.

Acerca do uso da internet, Lévy (1999) considera que essa seja o novo espaço de socialização, de contato e realização de práticas sociais entre os indivíduos, o que promove o nascimento da cultura do digital. Essa cultura, segundo o autor, expressa o surgimento de um universo diferente das formas culturais que vieram antes dele no sentido de que ele se constrói sobre a indeterminação de um sentido global qualquer (Lévy, 1999).

No âmbito específico das bibliotecas, a adesão às tecnologias digitais representou uma grande reviravolta nas tradicionais práticas bibliotecárias realizadas nessas instituições no decorrer dos tempos. A passagem do século XX para o XXI foi marcada por discussões, previsões e controvérsias a respeito da biblioteca do futuro.

Inúmeros estudos foram feitos no iniciar deste século. Encontra-se uma multiplicidade de nomenclaturas para identificar a biblioteca do século XXI e suas tecnologias. Segundo revisão de literatura realizada por Ohira e Prado (2002), os estudos dessa época apontam a existência da biblioteca eletrônica, biblioteca polimídia, biblioteca digital e biblioteca virtual e até sobre biblioteca do futuro. No entanto, segundo os autores, as terminologias mais emergentes e que utilizam diversas tecnologias são as bibliotecas denominadas de digitais e virtuais. 
Levacov (1997) caracterizou a biblioteca virtual como um espaço sem muros e com livros sem páginas, caracterizada pela substituição do papel pelo documento eletrônico e pela ampliação do acesso possibilitado pela digitalização. Cunha (2010) entende a biblioteca digital como aquela que contempla diferentes tecnologias e digitaliza suas coleções, informatizando os serviços oferecidos à clientela. Passados quase vinte anos da chegada do século XXI, pergunta-se: como a literatura vem tratando esse assunto? Houve consenso entre os teóricos sobre bibliotecas digitais e virtuais? Quais os serviços e produtos que as bibliotecas oferecem na contemporaneidade?

O artigo que se apresenta tem a intenção de realizar uma pesquisa bibliográfica, assim como fez Levacov (1997), Marchiori (1997), Ohira e Prado (2002) e Silva (2007), tendo em vista verificar os principais assuntos discorridos na literatura e, por conseguinte, apresentar, também, aspectos quantitativos que caracterizam a produção científica sobre este tema. A partir desta pesquisa, é provável que sejam identificados, em linhas gerais, aspectos relacionados a produtos, serviços e práticas bibliotecárias que vêm sendo realizadas nas bibliotecas do presente.

Oartigoé parte de uma pesquisa mais abrangente, ainda em desenvolvimento, em que foram selecionadas para análise, apenas, artigos científicos publicados em periódicos, considerando-se os últimos dez anos (de 2010 a 2019). Com o intuito de facilitar a apresentação dos resultados, o estudo foi dividido em duas etapas: na primeira, a busca pelos trabalhos foi realizada considerando o intervalo de tempo de 2010 a 2014. Já a segunda etapa contemplará os artigos publicados de 2015 a 2019. Este texto discorre os procedimentos realizados na primeira etapa.

Trata-se de uma pesquisa de natureza qualiquantitativa, pois, após a seleção dos trabalhos, são analisados os conteúdos deles, como também dados bibliométricos, com menção aos principais conteúdos abordados, as datas de publicação dos artigos, às autorias e aos canais de comunicação científica. Entende-se que, ao mesclar dados qualitativos e quantitativos, o estudo torna-se mais detalhado, apresentando, dessa forma, o estado da arte sobre o assunto.

\section{Metodologia}

Este estudo caracteriza-se como uma pesquisa descritiva, visto que são apresentados dados que demonstram o estado bibliográfico sobre um tema, considerando os apontamentos apresentados na literatura especializada. Quanto aos procedimentos técnicos, realizou-se uma pesquisa bibliográfica, com o objetivo de levantar e mapear os trabalhos até então publicados no âmbito da temática estudada e, a partir desse levantamento, fornecer os elementos utilizados pelos pesquisadores nas análises feitas em cada estudo identificado.

Considera-se que este estudo caracteriza-se como bibliográfico, pois foram utilizados procedimentos de identificação, seleção e avaliação das fontes de pesquisa para coletar e analisar criticamente os dados de estudos incluídos na amostra de análise (Clarke e Horton, 2001). Assim, o percurso metodológico foi realizado considerando três principais atividades: 1 - identificação das fontes; 2 - seleção da amostra de pesquisa; e 3 - síntese e avaliação dos trabalhos, conforme apresentado na proposta de Clarke e Horton (2001). 
Quanto à abordagem, este estudo é qualiquantitivo, pois foram analisados dados tanto de conteúdo dos artigos, como também foram quantificados dados bibliométricos. Nos estudos qualiquantitivos, segundo Creswell (2014, p. 30), "[...] o pragmatismo abre as portas para métodos múltiplos, diferentes visões de mundo e diferentes suposições, além de diferentes formas de coleta e análise de dados [...]". Por sua vez, os estudos bibliométricos visam quantificar a produção científica, mediante a apresentação de determinadas características dos trabalhos analisados e com a determinação de indicadores de qualidade e produtividade (Sancho, 1990).

A técnica para seleção da amostra foi o levantamento realizado em bases de dados científicas e Portal de Periódicos. Na sequência, os dados foram analisados por meio da análise de conteúdo. O levantamento, segundo Gil (2010), é a busca de dados em um local específico para fins de apresentação e comparação; já a análise de conteúdo, para Bardin (2011), representa o procedimento de extração dos assuntos contidos em um documento, haja vista formular conclusões acerca de como o assunto tem sido tratado pela comunidade científica.

Ao utilizar a análise de conteúdo, recorreu-se à categorização, como atividade de organização dos trabalhos, considerando os assuntos abordados a partir de semelhanças existentes entre eles. Segundo Bardin (2011), as categorias de análises são classes ou rubricas definidas a priori ou a posteriori, com o fim de permitir o alinhamento dos documentos (agrupamento) em razão dos caracteres comuns dos elementos constitutivos desses documentos analisados.

\subsection{Busca e seleção das fontes de pesquisa}

As publicações selecionadas referem-se a trabalhos (artigos científicos) publicados sobre a temática em apreço, ou seja, "Bibliotecas Digitais" e "Bibliotecas Virtuais". Em virtude da multiplicidade de termos utilizados para representar as bibliotecas que aderem às tecnologias digitais, consideraramse, no levantamento, apenas os termos "Bibliotecas Digitais" e "Bibliotecas Virtuais", haja vista serem esses os termos mais utilizados, conforme constatado na revisão de Ohira e Prado (2002).

Tendo como base as etapas que podem sustentar um estudo teórico, como mencionado na obra de Clarke e Horton (2001), foram realizados, sequenciamente, três fases ou procedimentos: identificação das fontes, seleção da amostra e síntese dos conteúdos dos trabalhos. Reforça-se que, para este artigo, foi acrescentada uma quarta fase, em que foram apresentados os dados bibliométricos das publicações.

Assim, na fase de identificação dos trabalhos, foi realizada a busca em duas bases de dados: Scientific Electronic Library Online (SciELO) e Base de Dados de Periódicos em Ciência da Informação (BRAPCI), além da busca no Portal de Periódicos da Coordenação do Pessoal de Nível Superior no Brasil (CAPES). A escolha por esses recursos deve-se à importância que eles exercem no armazenamento e disseminação da produção científica brasileira. O Portal de Periódicos da Capes e a SciELO fortalecem a visibilidade da produção científica, haja vista o alcance internacional que possuem, em diferentes domínios do conhecimento; já a BRAPCl é considerada uma das maiores bases de dados que indexa a produção científica brasileira na área da Ciência da Informação. 
Além da definição dos recursos a serem utilizados para busca na literatura, fez necessário delimitar o idioma de publiucação dos artigos a serem analisados para coleta de dados. Com o intuito de levantar as evidências publicadas na literatura brasileira, os trabalhos restringiram-se apenas àqueles que foram publicados no idioma português. Delimitou-se como espaço de tempo, os trabalhos publicados de 2010 a 2014, com o intervalo de cinco anos, sendo os próximos cinco anos (2015 a 2019) mapeados em estudo futuro.

Definidos os ambientes de investigação, a primeira atividade metodológica foi a busca pelas fontes de informação que formariam a amostragem da pesquisa. A busca foi feita utilizando os descritores "Bibliotecas Digitais" e "Bibliotecas Virtuais", e considerando essas palavras no título e no resumo dos artigos investigados.

Decorridas as atividades de busca e recuperação das fontes, com os resultados, procedeu-se à fase dois: a seleção das fontes para formação da amostra de pesquisa. Para tanto, foram realizadas leituras ao título e ao resumo de cada artigo. Com essa leitura, foi possível perceber que alguns não estavam relacionados à temática investigada, sendo eles descartados. Percebeu-se que alguns estavam repetidos, o que favoreceu a sua imediata exclusão da amostra de pesquisa.

\section{Resultados}

A partir das duas primeiras etapas realizadas, apresenta-se o total de trabalhos recuperados e selecionados para cada termo, nas três bases distintas e o total geral de trabalho para composição da amostra de pesquisa (Tabela 1).

TABELA 1

Apresentação dos trabalhos recuperados e selecionados, conforme descritores e fontes de pesquisa

\begin{tabular}{lcccccccc}
\hline DESCRITORES & \multicolumn{3}{c}{ TRABALHOS RECUPERADOS } & \multicolumn{5}{c}{ TRABALHOS SELECIONADOS } \\
& SciELO & BRAPCI & $\begin{array}{c}\text { Portal } \\
\text { CAPES }\end{array}$ & $\begin{array}{c}\text { Total } \\
\text { recuperados }\end{array}$ & SciELO & BRAPCI & $\begin{array}{c}\text { Portal } \\
\text { CAPES }\end{array}$ & $\begin{array}{c}\text { Total } \\
\text { selecionados }\end{array}$ \\
\hline Bibliotecas Digitais & 10 & 20 & 15 & 45 & 4 & 7 & 4 & 15 \\
Bibliotecas Virtuais & 4 & 5 & 7 & 20 & 1 & 4 & 1 & 6 \\
Total Geral & 7 & 9 & 31 & 47 & 5 & 11 & 5 & 21 \\
\hline
\end{tabular}

Fonte: Dados da pesquisa (2018).

O total de trabalhos recuperados foi de 47, que, após leitura, percebe-se que 21 estavam alinhados à temática da pesquisa. Esse total constitui a amostra de documentos ou fontes de informação em que foram interpretados, discutidos e apresentados os dados de conteúdo e bibliométricos, atividades essas realizadas nas etapas três e quatro e que serão discorridas na seção seguinte, destinada à análise e discussão dos dados. 
Além das atividades de busca, recuperação e leitura aos artigos, conforme descrito, atividades essas que compuseram a técnica de levantamento, outra técnica que fomentou o desenvolvimento deste estudo foi a análise de conteúdo. Portanto, a fim de se analisar o conteúdo das publicações, levou-se em consideração o procedimento de sistematização de categorias, conforme proposto pela análise de conteúdo.

Em linhas gerais, o objetivo dessa técnica é analisar os assuntos abordados no documento e relacioná-los com a temática em foco. Essa técnica é conceituada como "[...] um conjunto de instrumentos metodológicos cada vez mais sutis em constante aperfeiçoamento, que se aplicam a discursos (conteúdos e continentes) extremamente diversificados" (Bardin, 2011, p. 19). A autora ainda infere que "a intenção da análise de conteúdo é a inferência de conhecimentos relativos às condições de produção (ou, eventualmente, de recepção), inferência esta que recorre a indicadores (quantitativos ou não)" (Bardin, 2011, p. 19).

Para determinação dessas categorias, a partir da leitura ao resumo de cada artigo, identificou-se um assunto específico abordado no trabalho. Com essa identificação, os assuntos foram comparados, a ponto de serem sintetizados em um único e genérico assunto, relacionado a todos os demais, ou seja, as categorias foram estabelecidas, a posteriori, conforme as evidências constantes nos artigos selecionados.

Assim, foram delimitados os seguintes assuntos genéricos, que constituíram as categorais a serem discutidas, a saber: a) estruturação das bibliotecas; b) produtos e serviços oferecidos; c) educação e formação; e d) acesso e usabilidade da biblioteca. Essa divisão foi necessária, haja vista facilitar a síntese dos assuntos específicos de cada artigo, e, de modo relacional e comparativo, tornou-se oportuno realizar a sistematização dos trabalhos, evidenciando diferenças e semelhanças entre eles.

Após alinhamento dos trabalhos às respectivas categorias, eles foram, um a um, apresentados em uma Tabela, destacando o nome da categoria, a base na qual estavam indexados, a titulação da pesquisa, autoria e ano de publicação (Tabela 2).

TABELA 2

Composição da amostra: 21 artigos selecionados para análise

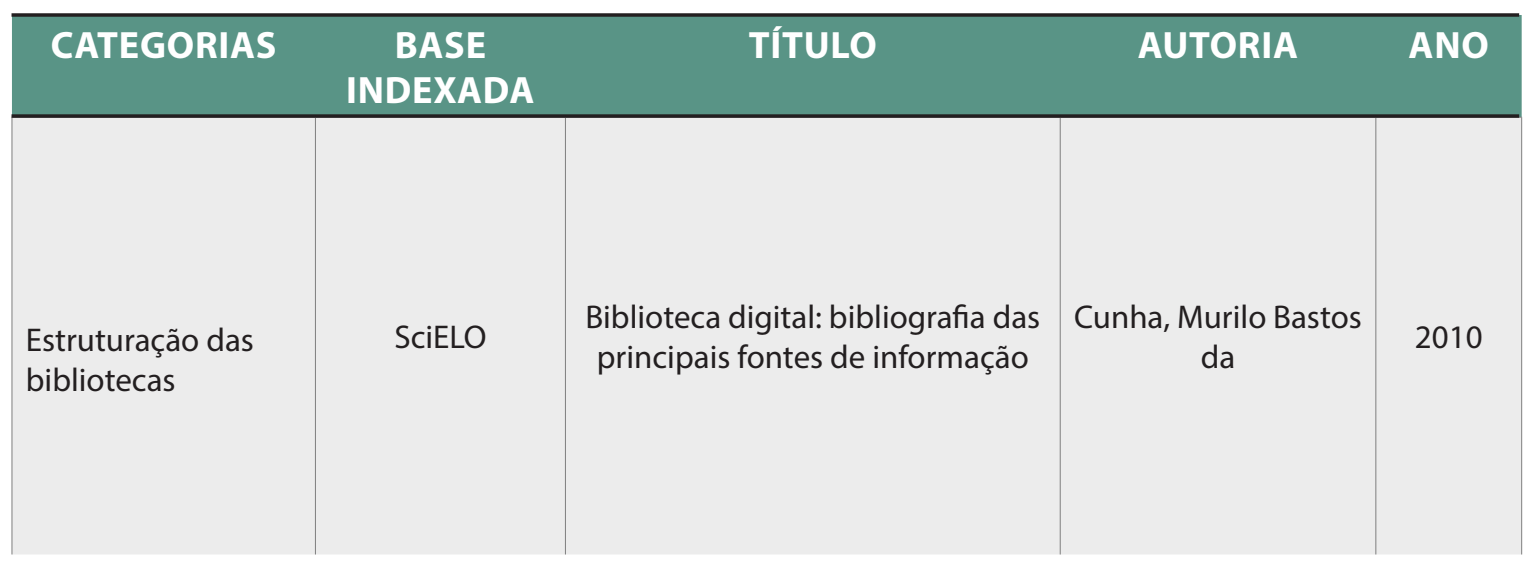


Continuación de la tabla 2

\begin{tabular}{|c|c|c|c|c|}
\hline CATEGORIAS & $\begin{array}{c}\text { BASE } \\
\text { INDEXADA }\end{array}$ & TÍTULO & TÍTULO & ANO \\
\hline \multirow{9}{*}{$\begin{array}{l}\text { Estruturação das } \\
\text { bibliotecas }\end{array}$} & BRAPCI & $\begin{array}{c}\text { Biblioteca digital de teses e } \\
\text { dissertações da UERJ: desafios e } \\
\text { oportunidades }\end{array}$ & $\begin{array}{l}\text { Bottari, Christina } \\
\text { Thereza Rachel e } \\
\text { Silva, Neusa Cardim }\end{array}$ & 2011 \\
\hline & BRAPCI & $\begin{array}{l}\text { Acesso aberto como estratégia } \\
\text { de disseminação e preservação } \\
\text { da produção científica discente: a } \\
\text { biblioteca digital de monografias } \\
\text { da Universidade de Brasília }\end{array}$ & $\begin{array}{c}\text { Freitas, Marilia } \\
\text { Augusta, Maia, } \\
\text { Luanna Cezar e Leite, } \\
\text { Fernando Cesar de } \\
\text { Lima }\end{array}$ & 2011 \\
\hline & BRAPCI & $\begin{array}{c}\text { Biblioteca digital sobre educação } \\
\text { a distância: favorecendo o acesso } \\
\text { ao acervo do Núcleo de Estudos } \\
\text { e Pesquisas em Competência } \\
\text { Informacional }\end{array}$ & $\begin{array}{l}\text { Vitorino, Elizete } \\
\text { Vieira e Isami, } \\
\text { Brenda Gonzalez }\end{array}$ & 2013 \\
\hline & BRAPCI & $\begin{array}{c}\text { Concepção de interfaces } \\
\text { para websites de bibliotecas } \\
\text { universitárias: projeto, elaboração } \\
\text { e gestão de informação em meio } \\
\text { digital }\end{array}$ & $\begin{array}{l}\text { Semeler, Alexandre } \\
\text { Ribas }\end{array}$ & 2013 \\
\hline & BRAPCI & $\begin{array}{l}\text { Biblioteca digital: uma evolução } \\
\text { da biblioteca convencional }\end{array}$ & $\begin{array}{c}\text { Santos, Carla } \\
\text { Marques dos e } \\
\text { Assunção, Suelene } \\
\text { Santana }\end{array}$ & 2013 \\
\hline & SCIELO & $\begin{array}{c}\text { A biblioteca nos tempos e } \\
\text { espaços digitais: novos e antigos } \\
\text { desafios }\end{array}$ & $\begin{array}{l}\text { Britto, Luiz Percival } \\
\text { Leme }\end{array}$ & 2014 \\
\hline & \multirow[t]{2}{*}{ BRAPCI } & \multirow{2}{*}{$\begin{array}{c}\text { Contribuição das ciências } \\
\text { cognitivas e da ciência da } \\
\text { informação para representação } \\
\text { da informação: proposta para } \\
\text { utilização na construção de } \\
\text { biblioteca virtual temática em } \\
\text { saúde }\end{array}$} & $\begin{array}{l}\text { Fonseca, Leandro } \\
\text { Guedes da, Amorim, } \\
\text { lara Rodrigues de, } \\
\text { Lourenço, Regina }\end{array}$ & \multirow[t]{2}{*}{2012} \\
\hline & & & $\begin{array}{l}\text { Goulart e Biolchini, } \\
\text { Jorge Calmon de } \\
\text { Almeida }\end{array}$ & \\
\hline & BRAPCI & $\begin{array}{l}\text { Biblioteca virtual em soluções } \\
\text { em tecnologia assistiva: como } \\
\text { começar? }\end{array}$ & $\begin{array}{l}\text { Coutinho, Kátia } \\
\text { Soares e Passerino, } \\
\text { Liliana Maria }\end{array}$ & 2014 \\
\hline \multirow{3}{*}{$\begin{array}{l}\text { Produtos e serviços } \\
\text { oferecidos }\end{array}$} & $\begin{array}{l}\text { Periódicos } \\
\text { Capes }\end{array}$ & $\begin{array}{l}\text { Portais de bibliotecas, sistemas } \\
\text { de avaliação de qualidade dos } \\
\text { serviços }\end{array}$ & $\begin{array}{l}\text { Santos, Alexandra e } \\
\text { Andrade, Antônio }\end{array}$ & 2010 \\
\hline & BRAPCI & $\begin{array}{l}\text { Serviço de referência virtual: } \\
\text { uma análise nas bibliotecas } \\
\text { universitárias de Natal }\end{array}$ & $\begin{array}{c}\text { Galvão Neto, } \\
\text { Sebastião Lopes e } \\
\text { Silva, Eliane Ferreira } \\
\text { da }\end{array}$ & 2010 \\
\hline & BRAPCI & $\begin{array}{l}\text { Serviço de referência virtual: } \\
\text { impantação do serviço de chat }\end{array}$ & $\begin{array}{c}\text { Nakano, Natália e } \\
\text { Jorente, Maria José } \\
\text { Vicentini }\end{array}$ & 2014 \\
\hline
\end{tabular}




\begin{tabular}{|c|c|c|c|c|}
\hline CATEGORIAS & $\begin{array}{c}\text { BASE } \\
\text { INDEXADA } \\
\end{array}$ & TÍTULO & TíTULO & ANO \\
\hline $\begin{array}{l}\text { Produtos e serviços } \\
\text { oferecidos }\end{array}$ & Periódico Capes & $\begin{array}{c}\text { Mídias sociais nas bibliotecas } \\
\text { universitárias brasileiras }\end{array}$ & Calil Junior, Alberto & 2013 \\
\hline \multirow{2}{*}{$\begin{array}{l}\text { Educação e } \\
\text { formação }\end{array}$} & $\begin{array}{l}\text { Periódicos } \\
\text { Capes }\end{array}$ & Educação e bibliotecas digitais & Furtado, Cassia & 2010 \\
\hline & SCIELO & $\begin{array}{c}\text { A formação do bibliotecário para } \\
\text { atuar em bibliotecas virtuais: uma } \\
\text { questão a aprofundar }\end{array}$ & $\begin{array}{l}\text { Madureira, Helania } \\
\text { Oliveira e Vilarinho, } \\
\text { Lúcia Regina Goulart }\end{array}$ & 2010 \\
\hline \multirow{6}{*}{$\begin{array}{l}\text { Acesso e } \\
\text { usabilidade da } \\
\text { biblioteca }\end{array}$} & $\begin{array}{l}\text { Periódicos } \\
\text { Capes }\end{array}$ & $\begin{array}{l}\text { Uso de bibliotecas digitais } \\
\text { de periódicos:um estudo } \\
\text { comparativo do Portal Capes } \\
\text { entre as áreas de conhecimento }\end{array}$ & $\begin{array}{l}\text { Cunha, Adriana } \\
\text { Áurea Lara e } \\
\text { Cendón, Beatriz } \\
\text { Valadares }\end{array}$ & 2010 \\
\hline & $\begin{array}{l}\text { Periódicos } \\
\text { Capes }\end{array}$ & $\begin{array}{c}\text { Taxonomia facetada como } \\
\text { interface para facilitar o acesso } \\
\text { à informação em bibilotecas } \\
\text { digitais }\end{array}$ & $\begin{array}{c}\text { Maculan, Benildes } \\
\text { Coura Moreira } \\
\text { dos Santos, Lima, } \\
\text { Gercina Ângela } \\
\text { Borém e Penido, } \\
\text { Patrícia }\end{array}$ & 2011 \\
\hline & BRAPCI & $\begin{array}{l}\text { Interatividade e usabilidade nas } \\
\text { bibliotecas digitais no processo } \\
\text { de ensino e aprendizagem }\end{array}$ & $\begin{array}{l}\text { Lima, Izabel França, } \\
\text { Souza, Renato Rocha } \\
\text { e Dias, Guilherme } \\
\text { Ataíde }\end{array}$ & 2012 \\
\hline & SCIELO & $\begin{array}{l}\text { A organização do conhecimento } \\
\text { em ambientes digitais: aplicação } \\
\text { da teoria da classificação facetada }\end{array}$ & $\begin{array}{l}\text { Pontes, Flávio Vieira } \\
\text { e Lima, Gercina } \\
\text { Ângela Borém de } \\
\text { Oliveira }\end{array}$ & 2012 \\
\hline & SCIELO & $\begin{array}{l}\text { Metodologia para avaliação } \\
\text { do nível de usabilidade de } \\
\text { bibliotecas digitais: um estudo na } \\
\text { Biblioteca Virtual de Saúde }\end{array}$ & $\begin{array}{l}\text { Lima, Izabel França } \\
\text { de, Oliveira, Henry } \\
\text { Pôncio Cruz de e } \\
\text { Santana, Sérgio } \\
\text { Rodrigues }\end{array}$ & 2013 \\
\hline & BRAPCI & $\begin{array}{c}\text { Bibliotecas digitais: um estudo } \\
\text { sobre o atendimento da } \\
\text { diversidade das necessidades dos } \\
\text { usuários }\end{array}$ & $\begin{array}{l}\text { Sá, Maria Irene da } \\
\text { Fonseca e Souza, } \\
\text { Rosali Fernandez de }\end{array}$ & 2014 \\
\hline
\end{tabular}


Por meio da leitura à Tabela 2, foi possível identificar alguns dados que podem ser mensurados, e que serão apresentados na parte destinada à análise dos dados bibliométricos. Também é possível perceber, pela leitura ao título das publicações, temas diversificados, contemplando questões teóricas e práticas. Os dados relacionados ao conteúdo das publicações são apresentados na seção seguinte.

\section{Discussão}

\subsection{Conteúdos das publicações}

Na categoria "estruturação das bibliotecas", identificou-se o trabalho de Cunha (2010). Nesse artigo, foi realizado um estudo bibliográfico, identificando uma gama de fontes de informação sobre bibliotecas digitais, tais como: bibliografias, livros e manuais, periódicos, eventos, lista de discussão, dentre outros. Ao discorrer sobre esses documentos, o autor frisa acerca de que, grande parte deles traça diretrizes para construção de websites, como também recomeda as atividades necessárias para instituir serviços em adequação aos usuários e, também, como garantir a preservação do material armazenado nas bibliotecas digitais (Cunha, 2010).

Também sobre estruturação de bibliotecas digitais, Bottari e Silva (2011) destacam a importância em se criar as bibliotecas de teses e dissertações, com o intuito de armazenar a produção científca das pesquisas defendidas nos Programas de Pós-Graduação das universidades brasileiras. Os autores ressaltam a importância do apoio técnico oferecido pelo Instituto Nacional de Ciência e Tecnologia, demonstrando, ainda, a necessidade de trabalho colaborativo em meio às novas interfaces e plataformas de disseminação da informação ofertadas aos usuários e que podem ser bem arquitetadas para garantir acesso aos metadados e texto integral dos trabalhos incorporados ao acervo dessas bibliotecas.

A preocupação em organizar a produção científica das instituições de ensino também é corroborada por Freitas, Maia e Leite (2011), ao exporem os procedimentos para criação da biblioteca digital de monografias de Graduação na Universidade de Brasília. Por meio da experiência relatada pelos autores, esse tipo de biblioteca pode ser instituída, primeiramente, com a definição de documentos regulamentadores, para, posteriormente, a aquisição do software que abrigará o acervo e a definição das atividades operacionais, na formação dos serviços a serem prestados.

No processo de criação da biblioteca digital, destaca-se como atividades principais, a seleção das fontes de informação que comporão o acervo, seguida da escolha do software, elaboração do espaço digital e a digitalização dos documentos impressos. Essas atividades precisam ser realizadas em consonância com o perfil da comunidade usuária, que, especificamente, para os usuários da Educação a Distância (EaD), é preciso oferecer serviços em atendimento às práticas educacionais conduzidas pelos docentes (Vitorino e Isami, 2013).

Semeler (2013) reflete acerca da construção e gestão dos websistes, sobretudo em bibliotecas universitárias. O estudo destaca a necessidade de capacitação do profissional, devendo o bibliotecário adquirir habilidade para trabalhar 
com projetos de design de navegação e outros elementos necessários à visibilidade das informações disponibilizadas na página da biblioteca, como a identidade visual e a oferta de sistemas que realizam a gestão de conteúdos (Semeler, 2013). Quanto ao processo de busca e recuperação da informação nas bibliotecas digitais, o autor reforça acerca da estruturação do catálogo de busca; é preciso disponibilizar um ambiente híbrido de forma que o usuário possa acessar os materiais de diferentes formas (Semeler, 2013).

O referido autor menciona ser necessário considerar a trindade: projeto, elaboração e gestão (Semeler, 2013). O projeto precisa ser a primeira etapa de construção de uma biblioteca digital, e determinará as etapas seguintes. Assim,

o projeto se define com a identificação do perfil de usuários, suas demandas de informação e pela elaboração dos wireframes do website. Isso porque identificar os usuários é tarefa fundamental para a proposição dos objetivos do site, bem como, a elaboração de projetos de design de navegação e identidade visual são estratégias norteadoras para o que vai ser implementado por meio de ferramentas tecnológicas e linguagens de programação (Semeler, 2013, p. 80).

A arquitetura e a estrutura de uma biblioteca digital precisam possuir as mesmas funcionalidades da biblioteca tradicional, visto que aquela é uma evolução dessa. Ademais, a concepção dessa biblioteca deve atender exigências relativas a alguns aspectos, como: processo de organização da informação, acesso à informação, aspectos econômicos e ações cooperativas (Santos e Assunção, 2013).

Britto (2014) concorda com Semeler (2013) ao frisar os desafios que se apontam na construção das bibliotecas digitais e destaca a necessidade de se criar uma política para nortear os procedimentos e as decisões a serem tomadas durante o processo de planejamento e execução. $\mathrm{O}$ autor esclarece que a política precisa conter os seguintes aspectos: a) constituição permanente do acervo; b) estímulo à produção e ao registro da memória; c) capacitação funcional continuada; e d) formação pública, incluindo promoção de estudos e pesquisas e estímulo permanente de atividades cultural e intelectual, além de ações diversificadas de disseminação da cultura (Britto, 2014).

Ademais, também aponta a existência de uma biblioteca, delimitada por espaçofísico, porém impregnada pela cultura digital, que ocasiona uma cultura individual e social. $\mathrm{O}$ autor defende mudanças das práticas bibliotecárias, sustentadas em políticas inovadoras que garantam a transformação da biblioteca em um espaço mais integrado e democrático (Brito, 2014).

Outro estudo que apresenta como foco a estruturação das bibliotecas digitais é o de Fonseca, Amorim, Lorenço e Biolchini (2012), ao descrever alguns apontamentos para criação de uma biblioteca especializada em saúde, que adeque-se às necessidades dos utilizadores. Os autores consideram que a informação precisa ser exposta de forma agradável e que seja representada de forma a facilitar sua recuperação, considerando um vocabulário que traduza os desejos dos usuários (Fonseca et al., 2012). Os autores também afirmam que:

As bibliotecas virtuais existentes não se preocupam com o perfil individualizado dos usuários, apresentando as informações de 
maneira única para qualquer tipo de usuário. Um salto de qualidade na elaboração de biblioteca virtual em saúde aqui proposta se deve justamente por levar o perfil individual do usuário em consideração, apresentando informações personalizadas para cada tipo de usuário de acordo com o seu perfil (Fonseca et al., 2012, p. 98).

Com o mesmo raciocínio de Fonseca et al. (2012), Coutinho e Passerino (2014) abordam o problema da adequação da biblioteca ao perfil e necessidades dos utilizadores. Para esses autores, é preciso considerar as pessoas com necessidades especiais, de modo que as tecnologias assistivas possam ser mais utilizadas, quando na estruturação dos serviços no ambiente digital. Segundo os autores, é necessário haver um melhor entendimento dos processos inclusivos no mundo do trabalho por parte dos gestores e demais colaboradores que se encarregam pela construção e gestão de bibliotecas digitais (Coutinho e Passerino, 2014).

Em síntese, quanto à estruturação de bibliotecas, os autores mencionam a necessidade de planejamento, visto que as diferentes atividades que podem ser oferecidas, tais como acesso a documentos, serviços de interação com os usuários, dentre outras precisam refletir as necessidades dos usuários. Com esse propósito, a estrutura da biblioteca envolve um conjunto de fazeres, com escolha adequada dos recursos tecnológicos, que possibilitem transferir para o ambiente digital os mesmos serviços e concepção de uma biblioteca tradicional.

Quanto à categoria "produtos e serviços", destaca-se o artigo de Santos e Andrade (2010). Os resultados desse trabalho indicaram que os serviços prestados nas bibliotecas digitais precisam, primeiramente, atender 0 quesito da satisfação dos usuários, sendo necessário passar por constantes processos avaliativos, para que possam ser melhor qualificados. É a avaliação dos serviços que norteará as mudanças a serem realizadas nas políticas e nas práticas profissionais. Ao avaliar os serviços oferecidos nos websites de bibliotecas, deve-se considerar diferentes aspectos, como: utilizadores, gestores do espaço, administradores do sistema e tecnologias de teste (cor, estado dos links, estrutura da informação, notoriedade face à concorrência, dentre outros detalhes (Santos e Andrade, 2010).

No âmbito dos serviços oferecidos em bibliotecas digitais, destacam-se os chamados serviços de referência. Eles precisam ser valorizados nas bibliotecas digitais, pois proporcionam a divulgação, com o intuito de permitir que o usuário usufrua de serviços personalizados mesmo no ambiente digital (Galvão Neto e Silva, 2010). Os resultados desse estudo demonstraram que o serviço de referência digital mais utilizado nas bibliotecas da cidade de Natal, estado do Rio Grande do Norte, é o correio eletrônico. Destaca-se que a referência digital é uma ferramenta facilitada da recuperação da informação, uma vez que possibilita a interação entre usuários e as fontes de informação, de modo que seja oferecida praticidade e rapidez nas consultas ao acervo da biblioteca, principalmente com o uso de mensagens instantâneas, como o chat, que garante a interação imediata do profissional com usuários (Nakano e Jorente, 2014).

Relacionado aos serviços oferecidos, é importante considerar, segundo o estudo de Calil Junior (2013), o potencial das mídias sociais, as quais promovem a interação entre a biblioteca e seus utilizadores, o que garante a divulgação dos produtos e serviços, além de fornecer o esclarecimento de dúvidas e diferentes auxílios que podem ser prestados por meio das redes de 
comunicação e interação na web. De acordo com os resultados alcançados, percebeu-se que a maioria das bibliotecas universitárias brasileiras ainda não possui mídias sociais para interação com usuários e divulgação dos serviços bibliotecários, resultado esse que recomenda a realização de estudos qualitativos sobre a realidade, como também estudos de uso das mídias sociais por parte dos usuários das bibliotecas (Calil Junior, 2013).

Sumariamente, quanto a produtos e serviços, os autores discorrem sobre a satisfação da comunidade usuária, que exerce papel fundamental para a melhoria do que é oferecido, mediante as práticas de avaliação. Essas práticas se potencializam quando há aproximação dos profissionais com os usuários, o que demonstra a importância dos serviços de referência, sobretudo no que tante à divulgação da unidade por diferentes canais de comunicação, com destaque ao uso dos recursos interativos, como as mídias sociais.

Na categoria "educação e formação", constata-se o trabalho de Furtado (2010), para quem, a biblioteca digital, assim como a tradicional, precisa exercer o papel de educadora junto a seu público. A autora presenciou uma lacuna em sua pesquisa, pois enquanto bibliotecas acadêmicas e públicas adentram-se ao ambiente digital, as bibliotecas escolares ainda permanecem com serviços distantes da atual realidade dos estudantes. Conclui que é preciso investir na criação de plataformas e ambientes digitais direcionados a públicos estudantes, tendo a escola como gestora e utilizando os produtos bibliotecários na internet para aproximar ainda mais os alunos das práticas pedagógicas (Furtado, 2010).

No que se refere à formação e capacitação bibliotecária tendo em vista atuar nas bibliotecas digitais, a pesquisa de Madureira e Vilarinho (2010) sinaliza a necessidade de reformulação nos currículos, oferecendo, especialmente, formação quanto ao uso dos novos suportes e gestão dos serviços oferecidos no ambiente web. Mediante uma discussão argumentativa, as autoras concluíram que a formação profissional e especializada para bibliotecários atuarem em bibliotecas digitais ainda é muito incipiente, sobretudo se comparar com o perfil demandado para o profissional da informação, na sociedade contemporânea (Madureira e Vilarinho, 2010). Também advertem para o fato de que, no contexto de criação e gestão das bibliotecas digitais, há preocupação com processos técnicos, especificamente no que tange à organização da informação nas bases de dados, não se priorizando o aperfeiçoamento/capacitação do profissional para atuar nesses espaços (Madureira e Vilarinho, 2010).

Resumidamente, quanto à educação e formação, a literatura investigada cita o papel da biblioteca como facilitadora na educação de seus usuários, com menção à biblioteca escolar, que muito pode contribuir no fortalecimento do aprendizado dos estudantes, ao firmar parcerias com professores quanto à oferta de material digital condizente com os conteúdos das disciplinas. A literatura também alerta acerca da formação do bibliotecário para atuar nas bibliotecas digitais, cabendo às escolas reformularem os currículos formativos, principalmente quanto ao uso de tecnologias digitais.

Relacionado à categoria "Acesso e usabilidade da biblioteca", o estudo de Cunha e Cendón (2010) reforçou o uso das bibliotecas digitais de periódicos científicos, enfatizando a necessidade de organização dos artigos por conteúdo e outros metadados suficientes para serem recuperados, conforme a usabilidade pelos pesquisadores em suas respectivas e específicas áreas de conhecimento. A pesquisa aponta o uso diferenciado da Biblioteca do Portal 
Capes, com conclusão de que "[...] não se deve formular hipóteses genéricas para as grandes áreas do conhecimento e que os fatores de uso e não uso são específicos para cada disciplina" (Cunha e Cendón, 2010, p. 70).

O artigo de Maculan, Lima e Penido (2011) descreve sobre o assunto da representação da informação para fins de recuparação em sistemas informatizados de bases de dados. O estudo esclarece que a taxonomia facetada pode funcionar como interface de busca, estruturando os dados de forma flexível, permitindo a opção de cruzamento de informações. Os resultados desse estudo demonstraram que "[...] a construção de sistemas de classificação mais flexíveis pode propiciar uma adequação ao desenvolvimento do conhecimento humano e permitir uma recuperação mais relevante às necessidades do usuário" (Maculan et al., 2011, p. 245).

No entendimento de Lima, Souza e Dias (2012), a interatividade e a usabilidade são fatores predominantes na biblioteca digital, a qual se caracteriza como um conjunto de serviços e objetos informacionais, estando esses elementos devidamente organizados, estruturados e apresentados, haja vista garantir a interatividade dos usuários com os objetos ou itens, que se encontram disponibilizados no espaço digital, de forma direta ou indireta. Defendem os autores que o uso da informação científica, nessas bibliotecas, contribui com o processo de ensino e aprendizagem, cabendo aos gestores da biblioteca oferecerem recursos que possibilitam a interação entre aluno, professor e bibliotecários (Lima et al., 2012).

Assim como mencionaram Maculan et al. (2011), acerca da teoria da classificação facetada para organização de documentos em bases e sistemas informatizados, Pontes e Lima (2012) também reforçam que as taxonomias dinâmicas projetadas de forma facetada "[...] requerem um esquema conceitual simples e são capazes de se adaptar a relacionamentos novos e não previstos, permitindo aos usuários descobrir esses relacionamentos nas operações de navegação e recuperação [...]" (Pontes e Lima, 2011, p. 37).

Outro estudo que versa sobre o tema do acesso e usabilidade nas bibliotecas digitais é o trabalho defendido por Lima, Oliveira e Santana (2013). Esses autores esclarecem que a participação do bibliotecário no ambiente da biblioteca digital deve ser por meio de constante monitoramento, visando aplicar procedimentos de usabilidade do ambiente virtual, de modo a satisfazer as necessidades dos usuários. Assim, inferem os autores acerca da participação intensa do profissional junto aos estudos de usabilidade da informação. Ademais, o experimento adotado na pesquisa, mediante aplicação de questionários aos usuários de uma biblioteca da área da Saúde, constatou um alto nível de usabilidade dos produtos e serviços oferecidos no ambiente digital, sendo esse nível considerado como "ótimo" (Lima et al., 2013).

O uso da informação armazenada nos acervos das bibliotecas digitais precisa ter como concepção, segundo a pesquisa de Sá e Souza (2014), um sistema de informação para identificar, localizar, buscar e disponibilizar aos usuários a informação que eles necessitam. Esse uso se faz mediante a identificação do usuário, para fins de conhecimento de suas características e perfis, de modo que a biblioteca reconfigura seus serviços, conforme as demandas potenciais. Assim, por meio de investigação in loco, realizada em algumas bibliotecas digitais, constatou-se que a identificação do usuário permitirá serviços diferenciados como, por exemplo, o fornecimento de informação que sirva à avaliação de programas de investigação aos órgãos fomentadores 
de pesquisa (Sá e Souza, 2014).

Em resumo, no que respeita a "Acesso e usabilidade da biblioteca", a literatura tem sinalizado como necessidade recorrente a gestão do acervo, que precisa ser realizada mediante a construção de ferramentas e sistemas capazes de representar o conteúdo dos documentos. Assim sendo, o acesso à informação será garantido, de modo a satisfazer necessidades, conforme diferentes perfis, e possibilitando a harmoniosa relação entre os membros da comunidade acadêmica.

\subsection{Dados bibliométricos}

A análise aos dados bibliométricos realizada neste artigo considerou os seguintes aspectos a serem mensurados: conteúdos principais abordados, datas de publicação dos artigos, autorias e os canais de publicação. O conteúdo restringiu-se às quatro categorias de análise utilizadas na etapa anterior (síntese dos assuntos); as datas de publicações dizem respeito ao ano de publicação, haja vista comparar o crescimento do número de artigos ao longo dos anos; nas autorias, considerou-se o número de autores por artigo (autoria única e coletiva); e, por fim, para os canais de comunicação, mapearam-se os periódicos que veicularam os artigos.

Quanto ao conteúdo dos artigos, "Estruturação de bibliotecas" e "Acesso e usabilidade" são temas que contemplaram mais da metade do número de publicações (Figura 1).

FIGURA 1

Conteúdos dos artigos: categorias de análise

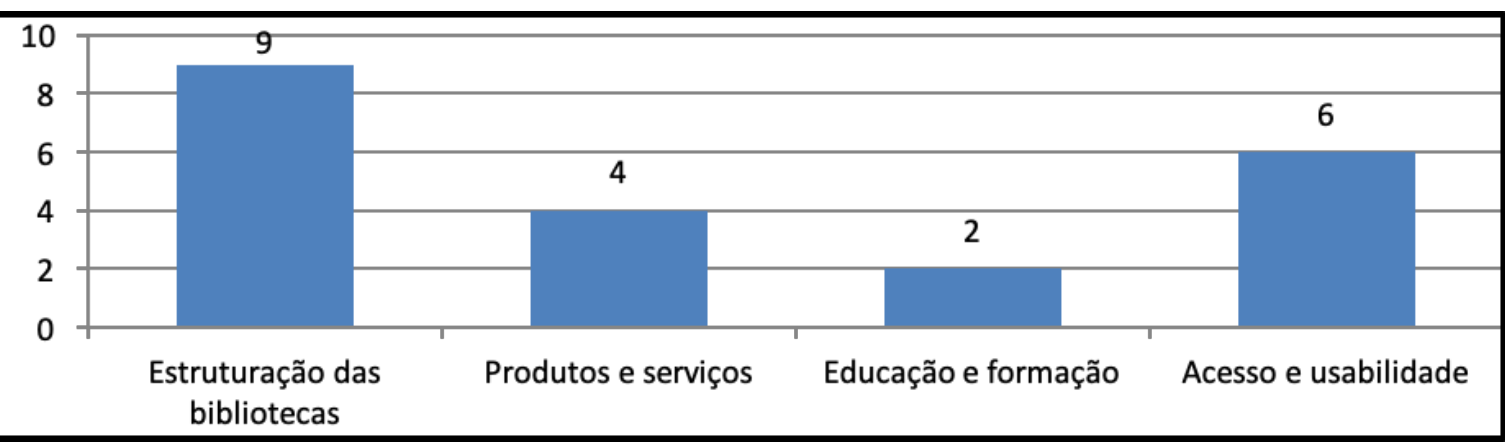

Fonte: Dados da pesquisa (2018).

Esse resultado se aproxima dos resultados alcançados com a revisão de literatura realizada por Ohira e Prado (2002). Nessa revisão, o tema mais discorrido foi "Metodologia de implantação", seguido por "Desenvolvimento do acervo digital" e "Impactos das tecnologias utilizadas".

Para Marchiori (1997), sobre o tema "Estruturação das bibliotecas", não resta dúvida que a implantação é decorrente de um processo longo e amplo, realizado por equipes multiprofissionais competentes e engajadas. O processo requer um trabalho de planejamento e gestão, sendo as fases inicial e final as mais problemáticas, o que exigirá que o pessoal de apoio e os clientes estejam envolvidos e vislumbrem que a iniciativa tem o objetivo de 
prover informação com valor agregado, disponibilizada mais rapidamente e em "pacotes" de informação mais efetivos (Marchiori, 1997).

Quanto ao assunto "Acesso e usabilidade", é importante dialogar com Levacov, ao apresentar fundamentos teóricos sobre a evolução das bibliotecas digitais e suas características. Para a autora, a essência da biblioteca é manter ou preservar a memória coletiva da humanidade (Levacov, 1997). No caso da internet, "[...] trata-se de uma memória coletiva distribuída, volátil, em constante transformação. A natureza destas informações parece requerer também que novas maneiras de tratamento sejam desenvolvidas [...]" (Levacov, 1997, p. 9).

Já para o assunto "Produtos e serviços", faz-se imprescindível, primordialmente, o conhecimento do público-alvo, para fins de adequação do que será oferecido. Com efeito, é importante que os bibliotecários “[...] participem do desenvolvimento de metaferramentas que permitam a estes usuários (com diferentes habilidades computacionais) recuperar eficientemente as informações desejadas em um ambiente informacional cada vez mais complexo" (Levacov, 1997, p. 3).

Mesmo que o tema "Educação e formação" não tenha tido destaque nos artigos analisados, não se pode deixar de atribuir-lhe o devido valor de importância, como foi mencionado na revisão realizada por Drabenstott e Burman (1997). As conclusões obtidas pelos autores reforçam que o bibliotecário precisa ir à luta, se capacitar para não perder postos de trabalho que a ele é designado, haja vista suas competências, sobretudo no que tange à organização da informação digital. E ainda mencionam que faz-se necessário "[...] aproveitar a oportunidade para demonstrar a importância de seus conhecimentos, experiência e identificação profissional na manipulação da informação e atendimento aos usuários, bem como se assente qual seja o seu novo 'fazer' neste contexto digital" (Drabenstott e Burman, 1997, p. 15, grifo do autor).

É importante destacar, também, acerca dos termos utilizados nos artigos, se "Biblioteca Digital", se "Biblioteca Virtual". A amostra de pesquisa demonstra que a maioria dos artigos (15 artigos) fizeram menção ao primeiro termo, ao passo que seis artigos utilizaram o segundo termo. Esse resultado também foi constatado nos estudos de revisão realizados por Levacov (1997), Marchiori (1997), Ohira e Prado (2002) e Silva (2007).

Os resultados revelaram a preocupação dos estudos com a construção das bibliotecas digitais, com destaque aos desafios que permeiam esse fazer. No entanto, a literatura aponta, também, a importância atribuída aos produtos e serviços informacionais e como esses têm sido utilizados pela comunidade. Além disso, a formação do profissional e o papel educativo da biblioteca são preocupações da comunidade científica.

Os dados referentes aos anos de publicações, considerando tempo delimitado de análise, ou seja, de 2010 a 2014, revelaram que houve publicação ao longo de todos os anos, não sendo percebida diferença substancial no número de artigos publicados em cada ano (Figura 2). 
FIGURA 2

Número de artigos publicados ao longo dos anos

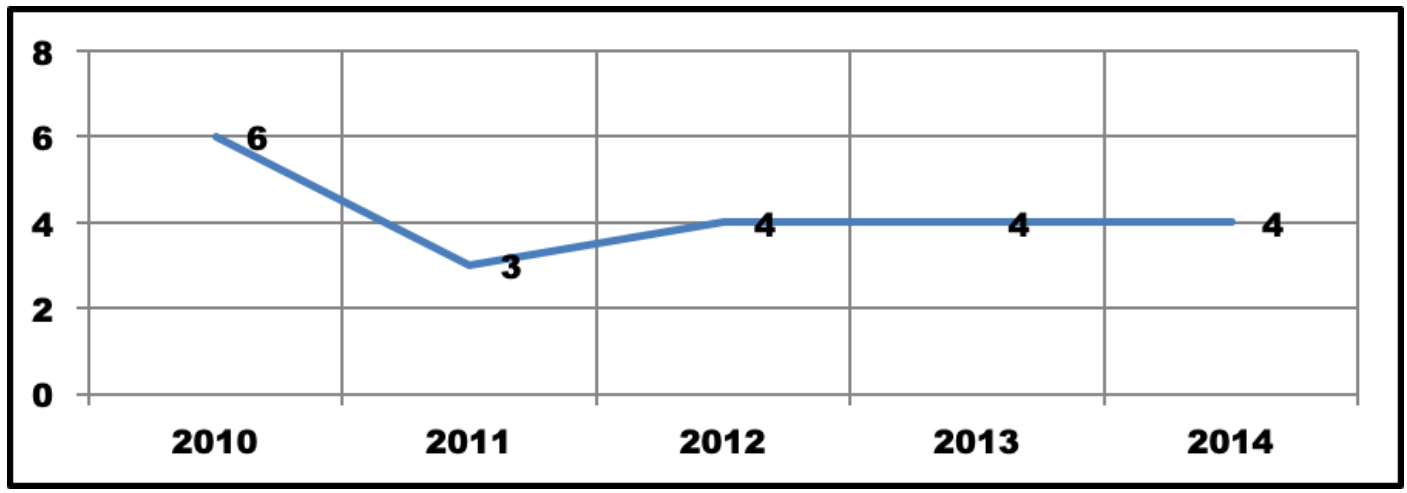

Fonte: Dados da pesquisa (2018).

A existência de publicações em todos os anos infere acerca de que o tema tem despertado interesse de pesquisa na área de Biblioteconomia e Ciência da Informação. O estudo de Silva (2007) também corrobora esse resultado, enfatizando, ainda que, no âmbito da temática "Bibliotecas Digitais/Virtuais", haver uma diversidade de assuntos trabalhados, tais como: "Redes", "Online", "Telecomunicações", "Informática", "Sistemas", "Mídias" e "Tecnologias". Além disso, o citado estudo detecta que, embora o tema tenha aparecido no decorrer das últimas décadas do século XX, é apenas a partir do ano 2000, que houve maior interesse de investigação por parte da comunidade científica.

Os resultados demonstram quantidade estável de trabalhos ao longo do tempo, o que pode indicar a presença de desafios ainda não superados e maior amadurecimento sobre a construção e uso das bibliotecas no ambiente digital. Dessa forma, é possível haver maior interesse pelo tema, nos próximos anos, sobretudo com o crescimento da informatização dos serviços bibliotecários.

A análise da quantidade de autores nos artigos indicaram que houve predominância da autoria coletiva em detrimento à autoria única, embora essa última esteja presente em cinco trabalhos. Constatou-se a presença de 11 trabalhos contendo dois autores, quatro artigos com três autores e apenas um trabalho possui quatro autores (Figura 3).

FIGURA 3

Número de autores nos artigos

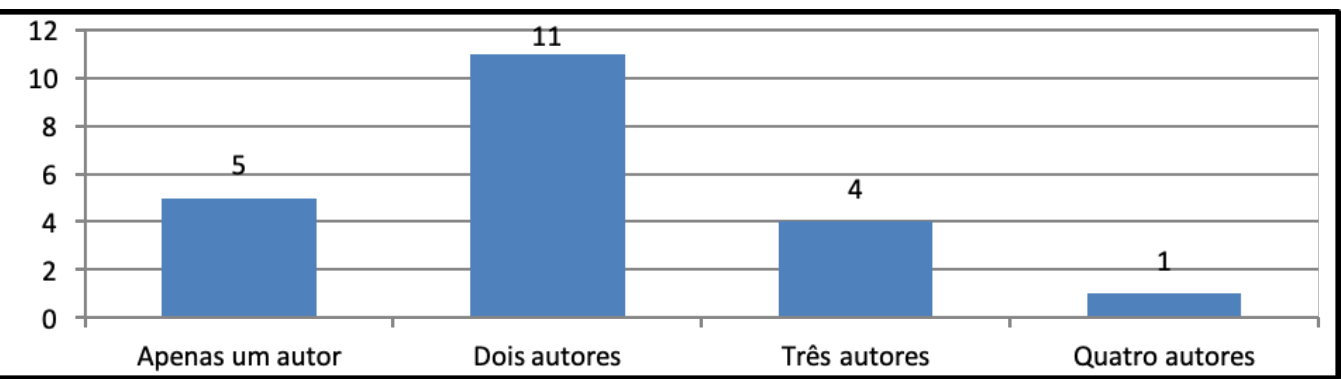


Esse resultado pode ser contextualizado com o estudo bibliométrico realizado por Queiroz e Vilan Filho (2018) acerca das autorias únicas e coletivas no âmbito da Ciência da Informação. O estudo mencionado demonstrou que, mesmo com a adesão, cada vez maior, da colaboração na produção científica, a autoria única ainda persiste, por diversas razões, sendo essa uma realidade nos estudos desenvolvidos no Brasil (Queiroz e Vilan Filho, 2018).

Especificamente sobre o tema"Bibliotecas Digitais/Virtuais", a revisão de Ohira e Prado (2002) identificou resultados contrários aos que são constatados neste artigo, pois, da amostra de 33 artigos, 18 deles foram elaborados individualmente, o que evidencia maior número de trabalhos com autoria única, ao contrário dos resultados descritos, neste estudo, visto que, aqui, a autoria coletiva teve maior prevalência.

A respeito dos canais de comunicação, ou seja, os periódicos que veicularam os artigos analisados, os dados demonstraram disparidade de revistas científicas, sendo elas pertencentes à área da comunicação e informação, com foco em Biblioteconomia e Ciência da Informação (Figura 4).

\section{FIGURA 4}

Periódicos que veicularam os artigos analisados

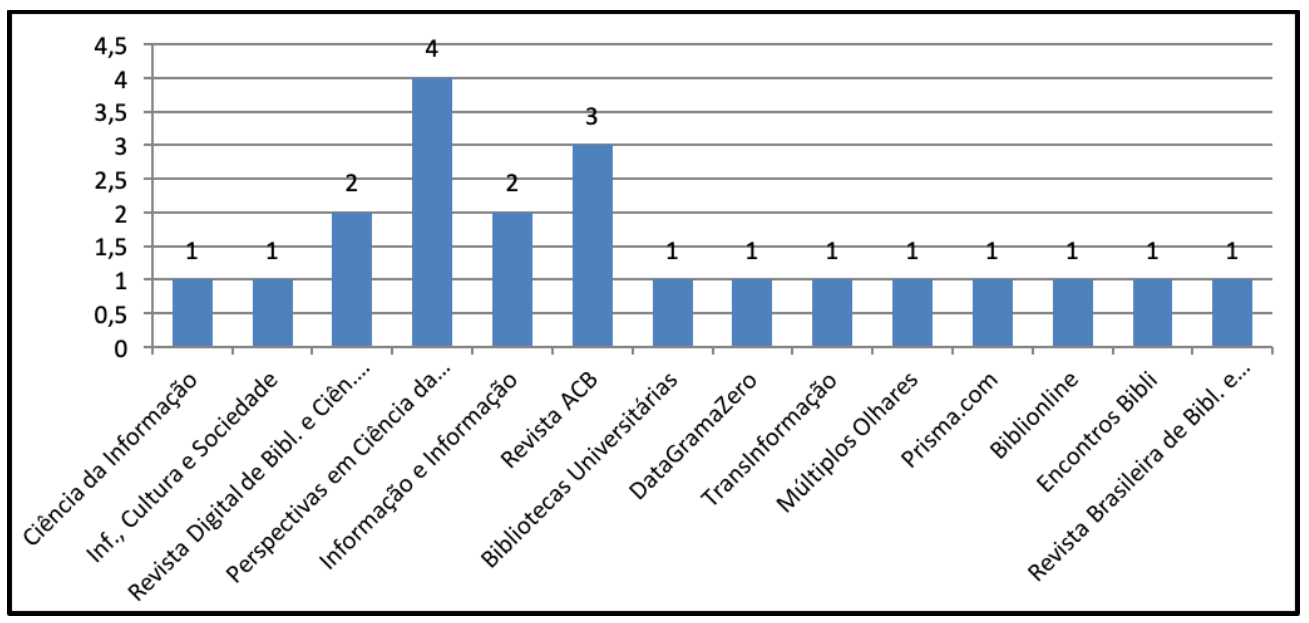

Fonte: Dados da pesquisa (2018).

Conforme consta na Figura 4, percebe-se que apenas uma revista não pertence a instituições brasileiras, a Prisma.com, sendo essa pertencente ao contexto de Portugal. A partir desse resultado, presume-se que os autores brasileiros, cujos artigos analisados, foram escritos em português, preferem publicar os estudos em revistas vinculadas a instituições de seu próprio país.

Considerando o número expressivo de periódicos que publicou os trabalhos (14 periódicos), entende-se que boa parte dos periódicos brasileiros da área de Biblioteconomia e Ciência da Informação foi contemplada. É possível identificar que apenas quatro periódicos se destacaram, entre eles: Perspectivas em Ciência da Informação (4 artigos); Revista ACB (3 trabalhos); Revista Digital de Bibilioteconomia e Ciência da Informação; e Informação e Informação, essas últimas, cada uma com dois trabalhos. As demais revistas publicaram apenas um artigo, o que demonstra uma distribuição homogênea entre os periódicos. Logo, pode-se inferir que o tema "Bibliotecas Digitais" e 
"Bibliotecas Virtuais" é um tema transversal, que perpassa diferentes âmbitos e contextos da Biblioteconomia e Ciência da Informação.

A partir da análise à quantidade dos autores presentes nos trabalhos e dos periódicos envolvidos, depreende-se que o tema é explorado por grupos de profissionais e pesquisadores, considerando os desafios existentes no dia a dia de trabalho desses sujeitos. Assim, a comunidade científica une esforços, seja no meio profissional ou acadêmico, no sentido de identificar os problemas existentes nas bibliotecas digitais/virtuais, e, a partir de pesquisas científicas, propor intervenções para adaptar a biblioteca ao contexto atual.

\section{Considerações Finais}

Os procedimentos realizados ao longo da pesquisa bibliográfica permitiram a identificação de 21 artigos científicos que contemplam diferentes assuntos relacionados ao tema "Bibliotecas Digitais" e "Bibliotecas Virtuais", que são: estruturação das bibliotecas, produtos e serviços oferecidos, educação e formação, e acesso e usabilidade da biblioteca.

Ao abordarem o assunto "Estruturação de bibliotecas", os estudos reforçam a importância de se estabecer um trabalho colaborativo, com profissionais capacitados e recursos adequados para execução das atividades. Os processos de trabalho precisam ser planejados e gerenciados, conduzidos por diferentes etapas, as quais se resumem a: estudo dos usuários e da instituição, formalização de documentos e políticas norteadoras, escolha dos recursos tecnológicos e atividades de organização e formação dos acervos digitais.

As discussões apresentadas nos trabalhos sobre "Produtos e serviços" revelaram, também, a necessidade de oferecer produtos e serviços em consonância com o perfil e necessidades dos utilizadores, estando esses serviços em processo constante de avaliação, em prol da qualidade do que é ofertado. Destaca-se, nos trabalhos analisados, a importância em se criar um serviço de referência, que preze pela divulgação e pelo atendimento ao usuário que recorre à biblioteca. Também é mencionado nos estudos o potencial das mídias sociais, haja vista viabilizar ampla divulgação e maior interação entre os agentes envolvidos.

Os trabalhos que versam sobre "Educação e formação" reforçam a necessidade de capacitação do profissional para atuar no ambiente das bibliotecas digitais. Isso exige a formação continuada do bibliotecário, como também maior aprofundamento do tema e outras estratégias criadas, como a inserção do tema em disciplinas do currículo formativo. Há reflexão, também, a respeito da função da biblioteca como instrumento pedagógico, facilitador de práticas educativas.

Quanto ao assunto "Acesso e usabilidade da biblioteca", os trabalhos são unânimes acerca da importância em se realizar estudos de uso, a fim de identificar mecanismos mais adequados para representação da informação nos sistemas de recuperação da informação das bibliotecas digitais. Há destaque quanto à contribuição da teoria facetada para representação de documentos, visto o potencial dela na descrição de conteúdos, na criação de relacionamentos entre os termos de busca e, principalmente, a possibilidade de garantir autonomia ao usuário no processo de busca e recuperação nos 
sistemas. Nesses trabalhos, também se constatou a participação intensa do bibliotecário/profissional da informação, com vistas a contribuir na organização e gestão dos acervos digitais.

Os dados quantitativos analisados demonstraram haver preferência pelo termo "Bibliotecas Digitais" ao termo "Bibliotecas Virtuais", com predominância dos assuntos "Estruturação de bibliotecas" e "Acesso e usabilidade". Em linhas gerais, os trabalhos foram publicados de forma equilibrada, ao longo dos anos, com predominância da autoria coletiva sobre a autoria única, e, por fim, houve distribuição uniforme entre boa parte dos periódicos da Ciência da Informação/Biblioteconomia, do Brasil.

A esse respeito, é possível constatar o interesse e engajamento da comunidade científica pelo tema, cujos esforços perpassem desde o contexto profissional até o acadêmico. A produção científica do tema, mesmo que ainda incipiente, estimula o desenvolvimento de novos estudos, o que pressupõe o crescimento do número de publicações e de autores envolvidos no decorrer dos próximos anos, principalmente, com a adesão acelerada aos recursos digitais da atualidade.

A importância do tema pressupõe o seu aprofundamento, sobretudo pelo fato do crescimento e uso, cada vez mais constante, das coleções digitais. Assim, estudos futuros precisam ser desenvolvidos, sejam eles de natureza teórica ou prática, no intuito de identificar conquistas, desafios e o estabelecimento de melhorias às bibliotecas inseridas no ambiente web.

Além disso, sugere-se a realização de outras revisões de literatura, de modo que seja possível identificar outros assuntos e/ou aspectos abordados na literatura sobre as bibliotecas digitais, tais como metodologias utilizadas para elaboração das pesquisas, percepções de profissionais e usuários, projetos práticos de implementação, dentre outros. Ademais, outra sugestão é comparar documentos ou normas internacionais acerca da gestão das bibliotecas digitais/virtuais, como também, boas práticas relatadas na literatura internacional, haja vista possibilitar uma análise comparativa.

As limitações da pesquisa (curto período de tempo analisado e artigos restritos ao idioma português) evidenciam o desenvolvimento de novas revisões. Portanto, é viável realizar revisões que abarquem estudos mais recentes, como, por exemplo, os últimos cinco anos (segunda etapa relativa a esta pesquisa, já em desenvolvimento), como também, trabalhos que analisem artigos publicados em outros idiomas, como o inglês e o espanhol, de modo a mapear a produção periódica em outras partes do mundo. 


\section{Referências}

Bardin, L. (2011). Análise de conteúdo. São Paulo, Brasil: Edições 70.

Bottari, C. T. R., Silva, N. C. (2011). Biblioteca digital de teses e dissertações da UERJ: desafios e oportunidades. Informação \& Informação, 16(1), 88-102. Recuperado de http://www.uel.br/revistas/uel/index.php/ informacao/article/view/7091/8480

Britto, L. P. L. (2014). A Biblioteca nos tempos e espaços digitais: novos e antigos desafios. Perspectivas em Ciência da Informação, 19(2), 7-17. Recuperado de http://www.scielo.br/pdf/pci/v19nspe/03.pdf

Calil Junior, A. (2013). Mídias sociais nas bibliotecas universitárias brasileiras. Revista $A C B, 18(2), 1053-1077$. Recuperado de https://revista.acbsc.org. $\mathrm{br} / \mathrm{racb} / \mathrm{article} / \mathrm{view} / 899$

Castells, M. (2005). A Sociedade em Rede: do conhecimento à ação política. Lisboa, Portugal: Imprensa Nacional.

Clarke, M. e Horton, R. (2001). Bringing it all together: Lancet Cochrane collaborate on systematic reviews. Lancet, 2(1), 357-378.

Coutinho, K. S. e Passerino, L. M. (2014). Biblioteca Virtual de Soluções em Tecnologia Assistiva: como começar?. Revista Brasileira de Biblioteconomia e Documentação, 10(1), 1-14. Recuperado de https:// rbbd.febab.org.br/rbbd/article/view/327/303

Creswell, J. (2014). Research design: qualitative, quantitative, and mixed methods approaches (4 Ed.). Los Angeles, Estados Unidos: London New.

Cunha, M. B. (2010). Biblioteca digital: bibliografia das principais fontes de informação. Ciência da Informação, 39(1), 88-107. Recuperado de http://www.scielo.br/pdf/ci/v39n1/v39n1a06.pdf 
Cunha, A. Á. e Cendón, B. V. (2010). Uso de bibliotecas digitais de periódicos: um estudo comparativo do uso do Portal de Periódicos da Capes entre as áreas de conhecimento. Perspectivas em Ciência da Informação, 15(1), 70-91. Recuperado de http://portaldeperiodicos.eci.ufmg.br/ index.php/pci/article/view/984/675

Drabenstott, K. e Burman, C. (1997). Revisão analítica da biblioteca do futuro. Ciência da Informação, 26(2), 1-15.

Fonseca, L. G., Amorim, I. R., Lourenço, R. G. e Biolchini, J. C. A. (2012). Contribuição das ciências cognitivas e da ciência da informação para representação da informação: proposta para utilização na construção de biblioteca virtual temática em saúde. Encontros Bibli, 17(1), 87109. Recuperado de https://periodicos.ufsc.br/index.php/eb/article/ view/1518-2924.2012v17nesp1p87/22724

Freitas, M. A., Maia, L. C. e Leite, F. C. L. (2011). Acesso aberto como estratégia de disseminação e preservação da produção científica discente: a Biblioteca Digital de Monografias da Universidade de Brasília. Bibliotecas Universitárias, 1(1), 71-80. Recuperado de http://repositorio. unb.br/handle/10482/9546

Furtado, C. (2010). Educação e bibliotecas digitais. Revista Digital de Biblioteconomia e Ciência da Informação, 8(1), 103-116. Recuperado de https://periodicos.sbu.unicamp.br/ojs/index.php/rdbci/article/ view/1950/2071

Galvão Neto, S. L. e Silva, E. F. (2010). Serviço de referência virtual: uma análise nas Bibliotecas Universitárias de Natal. Biblionline, 6(1), 72-81. Recuperado de http://www.periodicos.ufpb.br/ojs/index.php/biblio/ article/view/4904

Gil, A. C. (2010). Como elaborar projetos de pesquisa (5 Ed.). São Paulo, Brasil: Atlas.

Levacov, M. (1997). Bibliotecas virtuais: (r)evolução? Ciência da Informação, 26(2), 1-11.

Lévy, P. (1999). Cibercultura. São Paulo, Brasil: Editora 34. 
Lima, I. F., Oliveira, H. P. C. e Santana, S. R. (2013). Metodologia para avaliação do nível de usabilidade de bibliotecas digitais: um estudo na Biblioteca Virtual de Saúde. TransInformação, 25(2), 135-143. Recuperado de hhttp://www.scielo.br/pdf/tinf/v25n2/a04v25n2.pdf

Lima, I. F., Souza, R. R. e Dias, G. A. (2012). Interatividade e usabilidade nas bibliotecas digitais no processo de ensino e aprendizagem. DataGramaZero, 13(3), 1-8. Recuperado de http://www.brapci.inf.br/ index.php/article/download/53308

Maculan, B. C. S., Lima, G. A. B. e Penido, P. (2011). Taxonomia facetada como interface para facilitar o acesso à informação em bibilotecas digitais. Revista ACB: Biblioteconomia em Santa Catarina, 16(1), 234249. Recuperado de https://revista.acbsc.org.br/racb/article/view/746

Madureira, E. O. e Vilarinho, L. R. G. (2010). A formação do bibliotecário para atuar em bibliotecas digitais: uma questão a aprofundar. Perspectiva em Ciência da Informação, 15(2), 87-106. Recuperado de http://www. scielo.br/pdf/pci/v15n3/06.pdf

Marchiori, P. Z. (1997). Ciberteca ou biblioteca virtual: uma perspectiva de gerenciamento de recursos de informação. Ciência da Informação, 26(2), 1-10.

Nakano, N. e Jorente, M. J. V. (2014). Serviço de referência virtual: implementação do serviço de chat. Informação \& Informação, 19(1), 164-184. Recuperado de http://www.uel.br/revistas/uel/index.php/ informacao/article/view/15227/14212

Ohira, M. L. B. e Prado, N. S. (2002). Bibliotecas virtuais e digitais: análise de artigos de periódicos brasileiros (1995/2000). Ciência da Informação, $31(1), 61-74$.

Pontes, F. V. e Lima, G. A. B. (2012). A organização do conhecimento em ambientes digitais: aplicação da teoria da classificação facetada. Perspectivas em Ciência da Informação, 17(4), 18-40. Recuperado de http://www.scielo.br/pdf/pci/v17n4/03.pdf 
Queiroz, D. G. C. e Vilan Filho, J. L. (2018). Autoria única nos periódicos brasileiros das áreas de informação: em busca das razões. In: Encontro Nacional de Pesquisa em Ciência da Informação, 1., Londrina: UEL.

Sá, M. I. F. e Souza, R. F. (2014). Bibliotecas digitais: um estudo sobre o atendimento da diversidade das necessidades do usuário. Prisma. com, 25(1), 153-179. Recuperado de http://ojs.letras.up.pt/index.php/ prismacom/article/view/1873/1705

Sancho, R. (1990). Indicadores bibliométricos utilizados en la evaluación de la ciencia y la tecnologia. Revista Española de Documentación Científica, 13(3), 842-865.

Santos, A. e Andrade, A. (2010). Portais de bibliotecas sistemas de avaliação de qualidade dos serviços. Informação, Cultura e Sociedade, 22(1), 99118. Recuperado de http://www.scielo.org.ar/scielo.php?script=sci arttext\&pid=S1851-17402010000100005

Santos, C. M. e Assunção, S. S. (2013). Biblioteca digital: uma evolução da biblioteca convencional. Múltiplos Olhares em Ciência da Informação, 3(2), 1-10. Recuperado de http://portaldeperiodicos.eci.ufmg.br/ index.php/moci/article/view/2104/1304

Semeler, A. R. (2013). Concepção de interfaces para websites de bibliotecas universitárias: projeto, elaboração e gestão de informação em meio digital. Revista Digital de Biblioteconomia e Ciência da Informação, 11(1), 72-82. Recuperado de https://periodicos.sbu.unicamp.br/ojs/index. $\mathrm{php} / \mathrm{rdbci} / \mathrm{article} / \mathrm{view} / 1652$

Silva, M. C. F. (2007). Análise da evolução conceitual de"Biblioteca Eletrônica, Digital, Virtual e Polimídia, no período de 1993 a 2004 - na literatura de Ciência da Informação, no Brasil. In: Seminário Internacional de Bibliotecas Digitais, 1, São Paulo.

Vitorino, E. V. e Isami B. D. G. (2013). Biblioteca digital sobre Educação a Distância (EaD): favorecendo o acesso ao acervo do Núcleo de Estudos e Pesquisas em Competência Informacional (GPCIN). Revista ACB: Biblioteconomia em Santa Catarina, 18(1), 531-552. Recuperado de https://revista.acbsc.org.br/racb/article/view/861/pdf 


\section{e-Ciencias de la Información}

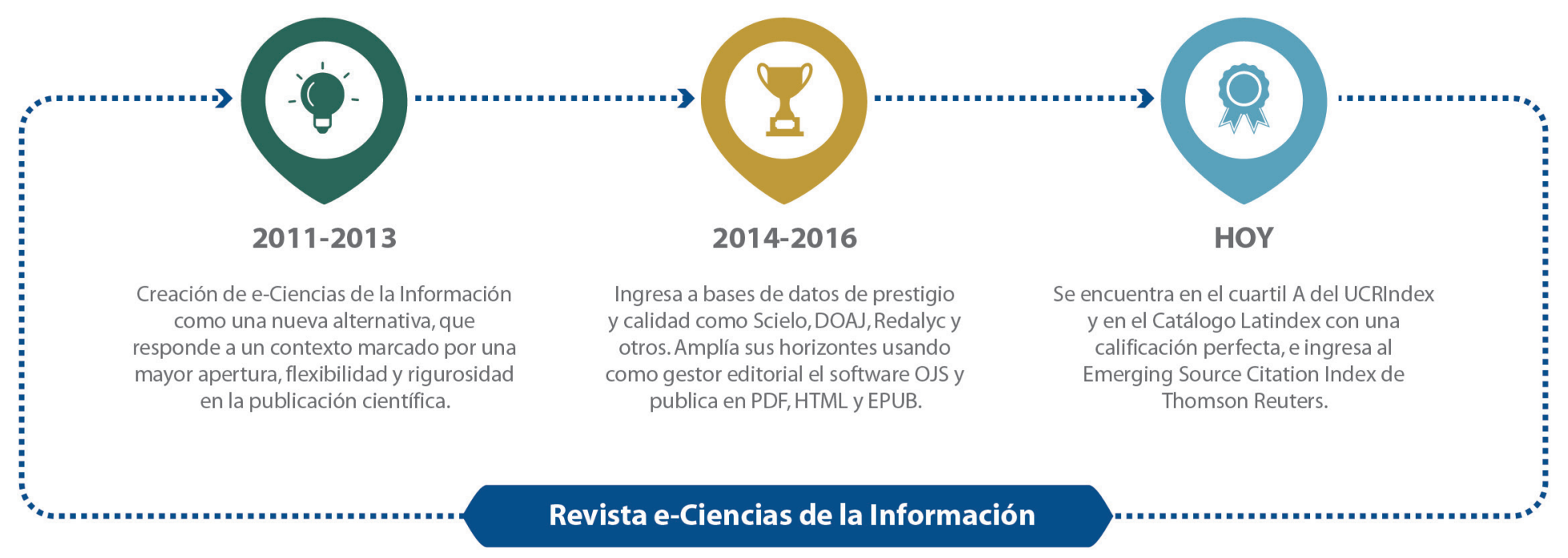

¿Dónde se encuentra idexada e-Ciencias de la Información?

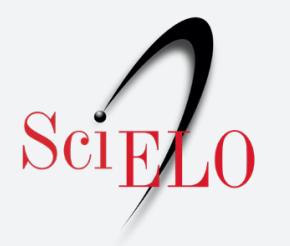

\section{latindex 12 clarivate Analytics}

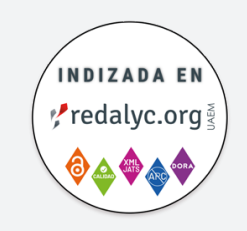

Para más información ingrese a nuestra lista completa de indexadores

¿Desea publicar su trabajo?

Ingrese aquí

O escríbanos a la siguiente dirección revista.ebci@ucr.ac.cr 